\title{
Impact of LMX on Coal Mine Safety Culture in China
}

\author{
Shuming Ma ${ }^{1}$, Jiangshi Zhang ${ }^{2}$ \\ ${ }^{1}$ CHINA-ASEAN International College, Dhurakij Pundit University, Bangkok 10210, Thailand; \\ ${ }^{2}$ School of Resources and Safety Engineering, China University of Mining and Technology, Beijing 100083, China
}

\begin{abstract}
Safety culture and the leader interaction with member are the keys to accident prevention. An equation of structure model (ESM) involved Leader-member exchange (LMX) and each element of safety culture is constructed based on literature review. And it is verified by this empirical study in China. 625 questionnaires are distributed and 333 valid samples are obtained with a response rate of $53 \%$ at coal mines. Research results from statistic analyses display safety culture is positively impacted by LMX. The conclusion gives advice to the practice of safety culture improvement by LMX promoting at coal mines in China.
\end{abstract}

Keywords-coal mine; Leader-member exchange (LMX); safety culture.

\section{INTRODUCTION}

As the important index of organization management, safety culture determines the efficiency of safety management ${ }^{[1]}$. It is emphasized as the first of the five keys of safety management by the government of China ${ }^{[2]}$. Some summarized papers even proposed that accident can be prevented by valid safety culture ${ }^{[3]}$.

Study relating to the element of safety culture is to be the fresh trend step by step in China ${ }^{[4]}$. Some conclusions illustrate that the factors which influence safety culture including leadership, organization structure, human resource, management system, strategy and flow path ${ }^{[5]}$. Leader, as one of the factors, is the initiator to the culture, whose behaviour develops safety culture crucially.

As well known, coal mine industry is the vital strategic energy to every country in the world. Unfortunately, the terrible safety situation still puzzles the managers of coal mines in China. Fatal accidents occur usually. Some studies pointed out that three defects which including the lack of leader safety awareness, the comprehension bias to safety culture, the improper method to safety improvement, which cause employees slack the safety problems, finally result in safety failure at coal mine industry in China ${ }^{[6]}$.

Well, research regarding how and the level of leadership conduct safety culture is almost a blank space in China. It is even brought to the forefront of attention by energy industry abroad since disasters happened occasionally since Three Mile Island reactor explosion ${ }^{[7]}$. More funds and technology subsidizes about safety control were invested into the programs relating the leadership and safety performance in USA. In the same way, the rules of the law ask for the safety responsibility of leaders in UK.

Based on these above, the research on the impact of leader-member exchange on safety culture is valuable to the practice of safety at coal mines in China. Meanwhile, the conclusion will provide empirical case then extend the theory of safety culture.

\section{LITERATURE REVIEW}

Sponsors: National Natural Science Foundation of China (No.51174209)

\section{A. Safety Culture}

Accident caution theory goes through four sections since it was proposed by Heinrich in $1950^{[8]}$. The first stage called technology cause which emphasize the integrity and reliability of the equipment ${ }^{[9]}$. The second stage underlined man-made error ${ }^{[10]}$. The third stressed society technology. Safety culture accenting team corporation in the organization culture was put forward since nucleus accident in $1986^{[11]}$. Since then safety culture was taken the responsibility to be investigated for serious accidents.

In short, safety culture is considered much important from organization to industry. The original proposals regarding safety culture were proceeded in the dangerous traditional industries, soon afterwards unfolded to all others $^{[12]}$.

\section{B. Leader-member exchange}

Since the traditional theory and early contingency theory are hard to account for the validity of leadership, Graen transferred the research point of leadership interacting with members. And proposed the Leader-member exchange theory (LMX) in $1975^{[13]}$. Differ from any other theory, LMX lay stress on leader interacting with members ${ }^{[14]}$, so the correlation to organazation behavior $^{[15]}$.

As the association to both the process and conclusion of leadership, LMX has been the focal point for more than 40 years. From theory to practice, LMX consider a successful leader set up efficient relationship with members seriously ${ }^{[16]}$.

\section{Literature of the relation between LMX and Safety Culture}

Tomas concluded the key of leadership to safety culture and the accident prevention ${ }^{[17]}$.Hofmann illustrated the relationship between leader and member impacting safety communication and forecasting safety performance ${ }^{[18]}$.In China, although most articles discussed safety culture 
without scientific methods, it still gives the orientation to develop the safety research in the future.

\section{RESEARCH HYPOTHESES}

The impact of LMX on safety culture is proposed as the Fig.1 followed.

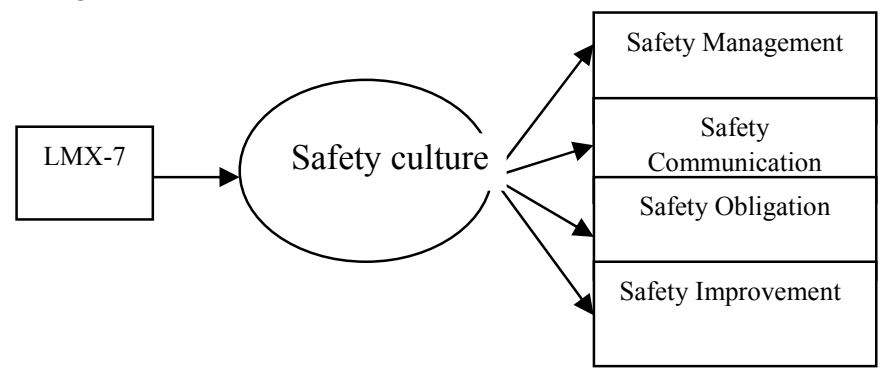

Figure 1. Model of the impact of LMX on each element of safety culture

Four hypotheses are put forward:

H1 LMX-7 impact safety management positively

H2 LMX-7 impact safety communication positively

H3 LMX-7 impact safety obligation positively

H4 LMX-7 impact safety improvement positively

\section{RESEARCH METHODS}

\section{A. Questionnaire survey}

Questionnaire survey was performed to collect data. 625 self-administered forms are distributed to the employees at coal mines with extent to the provinces all over China. Among the 531 feedbacks with completion anonymously,333 are selected by standard with the valid ratio at $53 \%$.Statistic methods including reliability, validity, correlation and the equation of structure model (SEM) are conducted data analyses.

\section{B. Measuring Scales}

LMX-7,the well-known one element scale developed by Graen, is selected to measure the degree of Leader and member interaction. The scale with 30 items developed by Cheyne is chosen to measure safety culture. Both scales adopt Likert5 style in this study. SPSS18.0 integrate with Amos 18.0 is conducted for data analyses.

\section{V.RESULTS ANALYSES}

\section{A. Reliability}

Reliability tests to the scales are conducted by SPSS18.0. Statistic results are showed as table 1 and table 2 .

TABLE I. RELIABILITY STATISTICS OF LMX-7

\begin{tabular}{c|c}
\hline$\alpha$ & Items \\
\hline 0.821 & 7 \\
\hline
\end{tabular}

Cronbach aof LMX-7 is 0.821 .And it is 0.845 of safety culture in this research on coal mines in China. Both data of results are greater than 0.7 , which meet the reliability standard of social research.
TABLE II. RELIABILITY STATISTICS OF SAFETY CULTURE

\begin{tabular}{c|c}
\hline$\alpha$ & Items \\
\hline 0.845 & 30 \\
\hline
\end{tabular}

Both scales which elected for data collection are according with the survey requirement in this paper.

\section{B. Validity}

Analysis results of factor loading with principle component extraction and $\max$ rotation indicate that LMX-7 is a single factor scale. And 5 elements are presented to the scale of safety culture. Confirmatory factor analysis is then conducted by Amos 18.0 to test discrimination validity. Four optimized factors which revised by the test are structured as safety management, safety communication, safety obligation and safety continuous improvement. The revised structure of safety culture is followed as Fig.2.

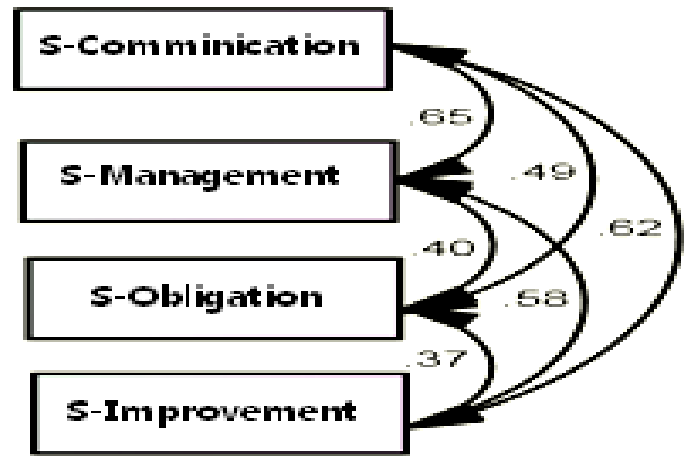

Figure 2. Revised structural model of safety culture

\section{Correlation}

Correlation analysis is subjected to verify the relationship between LMX-7 and safety culture. The result is showed as Table 3. The correlation coefficient is 0.300 with two-tailed at 0.01 level concomitant probabilities. This result proves LMX-7 positive correlating to safety culture significantly.

TABLE III. CORRELATION BETWEEN LMX-7 AND SAFETy CUltuRE

\begin{tabular}{l|l|c}
\hline & \multicolumn{1}{|c|}{ Index } & Safety culture \\
\hline \multirow{2}{*}{ LMX-7 } & $\begin{array}{l}\text { Correlation } \\
\text { coefficient }\end{array}$ & $\begin{array}{l}\text { Concomitant } \\
\text { probability }\end{array}$ \\
\cline { 2 - 3 } & Sample size & .000 \\
\cline { 2 - 3 } & Sam & 333 \\
\hline
\end{tabular}

\section{Equation of structure model}

Structural equation model relate to LMX-7 and safety culture is supposed based on the literature research. Fit measure investigating the reliability and validity of the model demonstrate the degree of consistency with the hypothesis and the practical data.8 indexes with benchmarks which showed as table 4 are selected on the basis of the test criterion to verify the model. The model is advised to revise when the goodness of fit index being out 
of the benchmark ${ }^{[19]}$.

Standardized fit summary of the hypothetical model is

showed as table 5 .

TABLE IV. MODEL FIT INDEXES WITH BENCHMARKS

\begin{tabular}{c|c}
\hline Index & Benchmark \\
\hline$\chi^{2}($ CMIN $)$ & $\mathrm{P}>0.05$ \\
\hline GFI & $>0.9$ \\
\hline AGFI & $>0.9$ \\
\hline RMSEA & $<0.08$ \\
\hline ECVI & $\begin{array}{c}\text { hypothetical model }<\text { indepentent model, hypothetical model }<\text { Saturated } \\
\text { model }\end{array}$ \\
\hline CFI & $>0.9$ \\
\hline NC & $1<$ NC<3( model meet a criterion) \\
\hline Significant level of estimate parameter & $>5$ (model has to revise) \\
\hline
\end{tabular}

TABLE V. STANDARDIZED MODEL FIT SUMMARY OF LMX-7 AND SAFETY CULTURE

\begin{tabular}{c|c|c|c|c|c|c|c|c}
\hline Model index & CMIN & P & DF & CMIN/DF & RMSEA & GFI & AGFI & CFI \\
\hline Hypothetical model & 33.433 & 0.000 & 9 & 3.715 & .090 & 0.966 & 0.922 & 0.824 \\
\hline
\end{tabular}

TABLE VI. StANDARDIZED REVISED Model FIt SUMmaRy BeTwEEN LMX-7 AND SAFETy CULTURE

\begin{tabular}{c|c|c|c|c|c|c|c|c}
\hline Model index & CMIN & DF & P & CMIN/DF & RMSEA & GFI & AGFI & CFI \\
\hline Revised Model & 7.81 & 5 & 0.167 & 1.562 & .041 & 0.991 & 0.972 & 0.976 \\
\hline
\end{tabular}

Freedom degree of this model is $21-12=9$. Chi-square of hypothetical model is 33.433 with $\mathrm{P}<0.05$. CMIN/DF is 3.715 $>3.000$. $\mathrm{RMSEA}=0.9 .>0.8, \mathrm{CFI}=0.824<0.9$, ECVI of hypothetical model is 0.173 , ECVI of saturated model is 0.127 , ECVI of independent model is 0.500. The results above define the reformulation to the hypothetical model. Re-inspect conduct with unreasonable items deleted in terms of conciseness principle and causal inference. Test results display as table6.

SEM of revised model is manifested as Fig. 3.

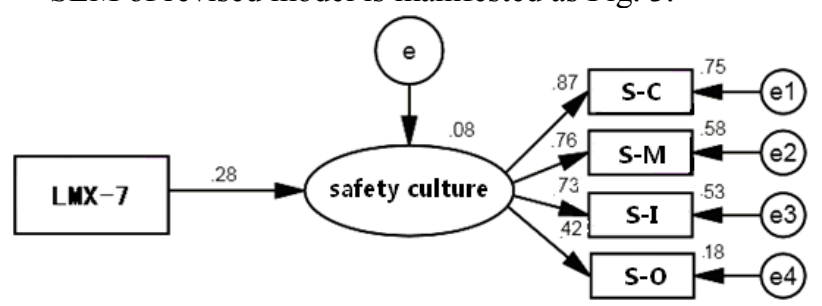

Figure 3. Revised standardized-model of the impact of LMX-7 on safety culture

Matching test of revised model indicates that the absolute value of C.R. of $\lambda$ is greater than 1.96 with $P>0.05$. Error variance is normal. ECVI of revised model is 0.084 . It meets the standard of

the data is less than the ECVI of independent model (0.412)and saturated model(0.090) . Chi-square value of the revised model is 7.81 with $\mathrm{P}=0.167>0.05$. Freedom degree is 5. $\mathrm{CMIN} / \mathrm{DF}=1.562<3.000 . \mathrm{RMSEA}=0.041<0.08$. GFI ,AGFI and CFI are all greater than 0.9. All indexes meet the benchmarks requirements. Revised standardized-model of the impact of LMX-7 on safety culture reflects the practical data with good adaptation degree.

R2 of revised SEM model is 0.08 which denotes that LMX-7 accounts for $8 \%$ general variance variation. Influence coefficient of the impact of LMX-7 on safety culture is 0.28 . According to the calculation with path coefficient, conclusions are showed that the impact coefficient of LMX-7 on safety communication is $0.28 * 0.87=0.24$, the coefficient on safety management is $0.28 * 0.76=0.21$, the coefficient on safety continuous improvement is $0.28 * 0.73=0.20$, the coefficient on safety obligation is $0.28 * 0.42=0.12$.

\section{CONCLUSIONS}

The fit tested and revised ESM of the impact of LMX on safety culture is proved by empirical study at coal mines in China. It shows LMX is the key to safety culture, impacts safety culture positively. In the same way, LMX as the independent variable influence on safety communication, safety management, safety obligation, and safety improvement positively.

Results of this study show that the improvement of safety culture can achieve though the LMX enhancement at coal mines. The verdict pushes the realistic purport to the construction of enterprise safety culture in China.

In conclusion, the findings of this research are not only to replenish empirical data but also to enrich the theoretical basis. 


\section{ACKNOWLEDGEMENTS}

Thanks to the ones who take part in this research. Acknowledge to the National Natural Science Foundation of China (No.51174209) for its support.

\section{REFERENCES}

[1] Glendon A I, Stanton N A. Perspectives on safety culture. Safety Science, 2000, 34: 43-72.

[2] Fu Gui et al. Investigations into the Impacts of Enterprise Safety Culture and its Quantitative Measuring [J].China Safety Science Journal, 2009, 19(1):86-92. (in Chinese)

[3] Li Xuandong. Function of safety culture to the accident prevention.Coal Mine Safety, 2004, 12. (in Chinese)

[4] Fang Dongping,Chen Yang. The connotation, pattern, evaluation and construction of safety culture in the construction industry. Architectural Economy, 2005, 2(268): 41-45. (in Chinese)

[5] Gao Kefu.Quantitative and qualitative methods to assess safety culture.Nucleus Safety.2005,3,7-13. (in Chinese)

[6] Yu Xijun. Study on construction and evaluation of safety culture system in China's coal enterprises [D]. Beijing: China University of Geosciences. 2007, 21-23. (in Chinese)

[7] Kemeny, J. G., \& United States. President's Commission on the Accident at Three Mile Island. Reports of the president's commission on the accident at three mile island. Washington, D.C.: The Commission : For sale by the Supt. of Docs., U.S. Govt. Print. Off. 1979.

[8] Heinrich, H. W.. Industrial accident prevention: A scientific approach. 3rd edition.McGraw Hill.1950.

[9] Wiegmann, D. A., and S. A. Shappell. Human error analysis of commercial aviation accidents:Application of the human factors analysis and classification system (HFACS). Aviation Space and
Environmental Medicine. 2001,72 (11): 1006-16.

[10] Rochlin, G. I., and A. Von Meier. Nuclear power operations: A cross-cultural perspective. AnnualReview of Energy Environment,1994, 19:153-87.

[11] Wilpert, B.. Organizational factors in nuclear safety. Paper presented at the Fifth International Association for Probabilistic Safety Assessment and Management, Osaka, Japan,2000.

[12] DeJoy, D. M., B. S. Schaffer, M. G. Wilson, R. J. Vandenberg, and M. M. Butts. . Creating safer workplaces: Assessing the determinants and role of safety climate. Journal of Safety Research,2004,35 (1): 81-90.

[13] Graen G B, Cashman C J. A role-making model of leadership in formal organizations: A developmental approach. In: H J G, L LL. Ed. Leadership frontiers. Kent State University Press: Kent, 1975. 143-166

[14] Gerstner, C. R., \& Day, D.V.. Meta-Analytic Review of Leader Member Exchange Theory: Correlates and constructs issues. Journal of Applied Psychology, 1997,82,827-844.

[15] Dienesch R M ,Liden R C. Leader-member exchange model of leadership : A critique and further development, Academy of Management Review, 1986 ,11, 618-634

[16] Graen, G. B.. To share of not to share leadership: New LMX-MMX network leadership or charismatic leadership creative projects. G. B. Graen \& J. A. Graen (Eds). Shared Network Leadership. Greenwich, CT: IAP-Information Age Publishing. 2006,26-36.

[17] Tomas, J. M., Melia, J.L., \& Oliver, A.M. , A cross validation of a structural equation model of accidents: organizational and psychological variables as predictors of work safety. Work and Stress, 1999,13(1), 49-58.

[18] Hofmaan DA, Morgeson FP. Safety-related behavior as a social exchange: the role of perceived organizational support and leader-member exchange. Journal of Applied Psychology.1999,84: 286-296.

[19] Bagozzi,R.P., \&Yi,Y.. On the evaluation of structural equation models. Academic of marketing science, 1988, 6,76-94. 